\title{
A JUVENTUDE FUTEBOLIZADA DE CANELA/RS
}

\section{THE FOOTBALLIZED YOUTH OF CANELA/RS}

\section{Rodrigo Koch*}

\section{RESUMO}

Este texto trata-se de uma descrição da cultura juvenil futebolizada na Região das Hortênsias, especialmente, do município de Canela/RS, que apresenta traços muito próximos do que Giulianotti (2012) caracteriza como o torcedor pós-moderno ou flâneur. O estudo utiliza metodologias pós-estruturalistas; porém, neste recorte são usados apenas métodos quanti-qualitativos. O objetivo desta investigação é compreender o processo contemporâneo da Futebolização e como este se relaciona com a construção das identidades juvenis na Região das Hortênsias. A futebolização dos jovens produz um sujeito com poucos vínculos com os clubes locais e, muito mais interessado no sucesso de agremiações e celebridades estrangeiras da modalidade.

Palavras-chave: Juventude; Futebolização; Canela.

\begin{abstract}
This text is a description of the youth culture footballed in the Region of the Hortensias, especially of the municipality of Canela/RS, which presents features very close to what Giulianotti (2012) characterizes as the postmodern fan or flâneur. The study uses poststructuralist methodologies; however, in this clipping only quantitative-qualitative methods are used. The objective of this research is to understand the contemporary process of Footballing and how it relates to the construction of juvenile identities in the Region of Hortensias. The footballing of young people produces a subject with few ties to local clubs and much more interested in the success of foreign associations and celebrities of the sport.
\end{abstract}

Keywords: Youth; Soccer; Canela.

"Professor Assistente e Diretor Regional - Campus II da Universidade Estadual do Rio Grande do Sul (Uergs). Mestre em Educação/Estudos Culturais e doutorando em Educação (Universidade Federal de Santa Maria - UFSM). 


\section{INTRODUÇÃO}

Este texto é um recorte da pesquisa de doutorado intitulada Identidades em construção: um olhar sobre a futebolização da juventude no Ensino Médio, desenvolvida na Universidade Federal de Santa Maria, no Rio Grande do Sul, desde 2015 e, agora, em fase final. Venho pesquisando o processo de futebolização entre crianças e jovens na escola desde 2011, com atenções maiores para as regiões metropolitana do Rio Grande do Sul (municípios de Porto Alegre e Gravataí) - em um primeiro momento (anos de $2011 \mathrm{e}$ 2012, no mestrado) - e, hortênsias (cidades de Canela, Gramado e São Francisco de Paula) - em uma segunda etapa. Trabalho com o seguinte problema de pesquisa: Em que medida o processo contemporâneo da futebolização se relaciona com a construção das identidades juvenis nas escolas públicas e privadas da Região das Hortênsias no Ensino Médio? Tenho ainda como preocupações (ou objetivos específicos da pesquisa), em como se expressam as identidades juvenis na escola, constituídas em grupos identificáveis, a partir de processos culturais globais e locais; quais são as condições locais e aspectos midiáticos que influenciam as identidades juvenis na contemporaneidade a partir da futebolização; e quais as produtividades da futebolização na construção das identidades juvenis e como estas são transformadas e veiculadas nos espaços escolares. Neste artigo, apresento dados coletados nesta última região, durante os anos de 2015, 2016 e 2017, que ainda requerem maiores análises, mas que já podem dar indicativos sobre o comportamento das culturas juvenis da contemporaneidade encontradas e vivenciadas neste espaço. Incialmente descrevo, de forma breve, o fenômeno pós-moderno da futebolização, para situar o leitor, e depois apresento os dados quantitativos que compõem esta pesquisa com alguns comentários iniciais sobre esta condição dos jovens. Em trabalhos futuros, novas análises serão acrescentadas.

\section{FUTEBOLIZAÇÃO}

A futebolização (KOCH 2012) - fruto da globalização a partir do futebol espetacularizado e mercantilizado, principalmente a partir dos anos 1990 - está imersa em um campo fluído que apresenta variações de tempos em tempos (sem que haja uma norma para cada período temporal) e, por isso, se transforma e se transfigura em cada espaço que penetra e a cada instante, adquirindo também contornos locais. Portanto, na construção do conceito ou na descrição do fenômeno globalizador, utilizei ou 'roubei' aportes/ideias de Zygmunt Bauman (2001) a respeito da modernidade líquida, de Gilles Lipovetsky (2016) sobre o mundo leve e, de Stuart Hall (1997), referente ao fenômeno da globalização, para contextualizar a sociedade contemporânea; de Nestor Garcia Canclini (2003), sobre hibridação, na tentativa da construção dos indivíduos que constituem tal sociedade; e de Guy Debord (2005) sobre a sociedade do espetáculo e a passagem para a sociedade 'midíocre', nas análises de Juremir Machado da Silva (2012). Utilizei também outros conceitos desses mesmos autores e outros autores que contribuem para descrever o processo pós-moderno da futebolização. Segui sugestões de pesquisadores contemporâneos que consideram o campo aberto para discussões; como por exemplo, Araújo (2015), que expõe a falta de possibilidades de se falar de uma ideia de esporte puro (ou moderno) na atualidade, justamente porque se faz necessário considerar sua espetacularização, sua virtualização e suas diferentes entradas sociais. Estudiosos e pesquisadores do futebol apontam agendas de pesquisa que permeiam sua(s) multiplicidade(s) de significações. Portanto, se não há um esporte pós-moderno, no mínimo há um esporte neomoderno que requer novas e constantes análises.

Não considero a futebolização um conceito e sim um fenômeno e/ou processo. Penso que a mesma pode também ser considerada uma pedagogia cultural. Desde a emergência dos Estudos Culturais - em Birmingham, na Inglaterra - a pedagogia passou a ser entendida como um mecanismo de ensinamento ou difusão de modos de ser e pensar, ou seja, a pedagogia não se limita a práticas escolares explícitas ou institucionalizadas: ela está na TV, em filmes, jornais, revistas, anúncios, videogames, aplicativos, brinquedos, e também nos esportes (STEINBERG 1997). O conceito ganhou espaço em pesquisas acadêmicas nas áreas da Educação e Comunicação. Andrade e Costa (2015) e Andrade (2015) apresentaram diferentes pesquisas que, tanto no campo da cultura como no da pedagogia, contribuíram para a ampliação da ideia sobre espaços de aprendizagem. Ao buscar elementos sobre a emergência do conceito de pedagogias culturais, as autoras destacam que uma das principais características do 
imperativo pedagógico contemporâneo é a existência de relações de ensino e aprendizagem em diferentes espaços sociais regulados pela cultura. Em resumo, uma pedagogia cultural pode ser qualquer mecanismo midiático ou social capaz de ensinar algo para alguém. Os exemplos mais comuns na contemporaneidade seriam os programas de TV ou os aplicativos de smartphones. Portanto, o fenômeno da futebolização também pode se encaixar no conceito de pedagogia cultural, pois o mesmo está imerso na cultura e sem dúvida alguma produz seus ensinamentos.

[...] o conceito de pedagogias culturais nos ajuda a entender os processos educativos de modo mais amplo, complexo e matizado. [...], parece que as pedagogias culturais em nossa sociedade visam garantir que a aprendizagem seja contínua, não se restringindo ao tempo e ao espaço da escola, permanecendo atuantes em muitos lugares ao longo da vida. (ANDRADE e COSTA 2015, p.61)

É importante, ainda, relembrar que o futebol se tornou, no último século, o principal esporte de massa do mundo, tendo espaço de destaque nos diversos canais da mídia em vários países, fato que ajudou e provocou a construção do próprio termo futebolização. $\mathrm{O}$ futebol agrega o povo, dando sentido de identidade e nação. É esporte, lazer, produto e cultura ao mesmo tempo (ALABARCES 2002).

[...] [O futebol] mexe com a paixão e com a vida de bilhões de pessoas. [...]. Não se trata de um simples jogo: o futebol é uma mistura de espetáculo e esporte; arte e diversão; competição e lazer. [...]. É o jogo de nossas vidas. (KOFF 2009, p. 8) [acréscimo meu]

De acordo com Giulianotti (2010) o futebol é uma das grandes instituições culturais, como a educação e a mídia, que formam e consolidam identidades nacionais no mundo inteiro. Completo tal pensamento com as afirmações de Damo (2015), que considera que o futebol produz e é fruto de "múltiplos circuitos, em geral consolidados a partir de fronteiras continentais, nacionais, regionais e até mesmo locais, conquanto estes últimos fiquem à margem da espetacularização". Para discutir esta questão, reafirmo que considerei adequado recorrer aos textos sobre 'hibridação', de Nestor Garcia Canclini, às referências de Stuart Hall sobre 'globalização', e ao conceito de 'sociedade do espetáculo', de Guy Debord, e relacioná-los com o futebol no tempo atual (modernidade líquida de Bauman e/ou hipermodernidade leve de Lipovetsky), entre outros.

\section{MAPEAMENTO QUANTITATIVO DA JUVENTUDE DO ENSINO MÉDIO EM ESCOLAS DA REGIÃO DAS HORTÊNSIAS}

Um primeiro passo de investigação, que aproveitei como ponto de partida para essa tese, foi realizado através de projeto de pesquisa de cunho exploratório sob minha coordenação, desenvolvido nos anos de 2015 e 2016, com fomento interno da Universidade Estadual do Rio Grande do Sul (Uergs) - a qual sou vinculado como professor assistente com dedicação exclusiva -, que contemplava alunos com bolsas de iniciação científica. Nesta etapa contei com a colaboração das acadêmicas Priscila Francisco de Oliveira Castilhos (bolsista IniCie-Uergs em 2015), Caroline Borges de Souza (bolsista IniCie-Uergs em 2016) e Priscila Damasceno da Silva (voluntária do projeto de pesquisa e orientanda de graduação) na coleta de dados e observações iniciais.

O projeto de pesquisa Identidades Juvenis nas Escolas da Região das Hortênsias, na área de Humanas-Educação, consistia em conhecer, identificar, descrever, classificar e monitorar as identidades juvenis na contemporaneidade em escolas públicas e privadas de três municípios da referida região: São Francisco de Paula (em 2015), Canela e Gramado (em 2016). As escolas escolhidas foram as que apresentavam o maior número de alunos matriculados no ensino médio nos respectivos municípios e redes de ensino. Este estudo teve como referencial as discussões acerca das identidades juvenis, com base teórica nos Estudos Culturais da juventude. Para a pesquisa de campo/coleta de dados foi adotada metodologia quantitativa, com questionário fechado. Este questionário solicitava dados iniciais como gênero e ano em que o entrevistado estava cursando o Ensino Médio, e apresentava uma série de opções de preferências/ interesses e grupos sociais onde os participantes que estavam respondendo podiam optar por mais de um item; inclusive, havia espaços/lacunas em branco para que os respondentes pudessem apontar opções que não foram contempladas na versão impressa. Optamos por realizar a aplicação dos questionários nas escolas por estas se tratarem de um espaço da juventude, e 
também pela questão prática de encontrar um maior número de jovens concentrados no mesmo local, sem que houvesse tendência ou preferência por um grupo social em detrimento dos outros, algo que poderia ocorrer se os dados fossem coletados em um shopping center, uma festa ou show musical, ou ainda um estádio de futebol entre outros espaços públicos possíveis. Considero importante apresentar a seguir a Região das Hortênsias em dados socioeconômicos que justificam a escolha desta região para a realização da pesquisa.

De acordo com Bertê et al. (2016), o Conselho Regional de Desenvolvimento (COREDE) Hortênsias foi criado em 1991, e é composto por sete municípios: Cambará do Sul, Canela, Gramado, Jaquirana, Nova Petrópolis, Picada Café e São Francisco de Paula. A região possui uma estrutura agrícola bastante diversificada, destacando-se produtos da lavoura temporária, como batata, alho e tomate, sendo que nos maiores municípios - nos campos de altitude - a silvicultura e a produção de bovinos de corte e de leite lideram. A Indústria de Transformação também é intensiva em emprego, com segmentos tradicionais como a produção de calçados, de móveis, de produtos de metal e laticínios. Apesar de reunidos em um mesmo COREDE, por questões geográficas e climáticas, os municípios que compõem a Região das Hortênsias apresentam grandes diferenças sociais e econômicas em seus eixos oeste (Nova Petrópolis, Picada Café, Gramado e Canela) e leste (São Francisco de Paula, Cambará do Sul e Jaquirana).

Os municípios do oeste possuem menor área, produção agropecuária em pequenas propriedades e concentram os melhores indicadores sociais, condições de infraestrutura e empregos no setor industrial do COREDE; os municípios do leste, situados nos campos de altitude, possuem maior área, problemas de infraestrutura e alguns dos mais baixos indicadores sociais do Estado, principalmente Jaquirana, que necessita, sobretudo, de políticas públicas voltadas à geração de renda e Educação Básica. Esse município também não possui acesso asfáltico, o que dificulta o escoamento da produção local. No turismo, também se constituem dois eixos: no oeste, ligado principalmente a atrativos culturais, com melhor aproveitamento econômico por parte dos municípios; e o leste, ligado ao turismo rural e contemplativo de belezas naturais, com deficiência de infraestrutura e com demandas de melhor aproveitamento de suas potencialidades. As cidades de Canela, Gramado e
Nova Petrópolis, no eixo oeste, destacam-se pela organização da gestão turística [...] (BERTÊ et al. 2016, p.337).

Vale destacar também sobre a Região das Hortênsias que segundo dados de 2010 do IBGE (Instituto Brasileiro de Geografia e Estatística), a mesma possui cerca de $80 \%$ de sua população em áreas urbanas, e os outros $20 \%$ dos habitantes em espaços rurais. O município mais populoso é Canela com mais de 30 mil habitantes, enquanto que outros três (Nova Petrópolis, Gramado e São Francisco de Paula) ficam na faixa entre 15 e 30 mil habitantes. Os demais apresentam índices menores, ou seja, populações abaixo de 10 mil habitantes. Os municípios do COREDE Hortênsias são polarizados econômica e socialmente pela capital regional de Caxias do Sul.

Em 2012, o Índice de Desenvolvimento Socioeconômico (IDESE) da Região das Hortênsias encontrava-se no Nível Médio de desenvolvimento. Analisando os índices do IDESE, verifica-se que os blocos Saúde, Educação, e Renda estão em posições médias em relação ao Estado do Rio Grande do Sul, ou seja, a região não se destaca nem por estar entre as primeiras e tão menos por ocupar as últimas posições, ainda que - como já citado - haja certas discrepâncias sociais e econômicas entre os municípios que a compõem. No Bloco Educação, destaca-se o índice do sub-bloco Ensino Médio (Taxa de Matrícula no Ensino Médio), ocupando a terceira posição no Estado.

Segundo Bertê et al. (2016), com base nessa caracterização e em trabalhos anteriores, pode-se destacar como iniciativas promissoras para a Região: fomento ao turismo (ecoturismo, turismo de aventura e rural), apoio à produção agropecuária, e melhorias na infraestrutura. Por outro lado, há questões que merecem atenção especial de acordo com os autores, como: fragilidades ambientais, perda de competitividade do setor industrial, baixos indicadores sociais relativos à educação (destaca-se a baixa taxa de matrícula na Pré-Escola, o baixo desempenho dos alunos do Ensino Fundamental na Prova Brasil e o alto percentual de adultos com Ensino Fundamental incompleto), saúde e renda, e envelhecimento populacional. Saliento que após decidir por pesquisar nesta região, na qual estou inserido profissionalmente nos últimos cinco anos, destaquei os municípios de Gramado, Canela e São 
Francisco de Paula pelos mesmos estarem entre os mais povoados do COREDE Hortênsias e, também por apresentarem características socioeconômicas diferentes dentro da região, que poderão proporcionar melhores análises. Não se trata de uma região metropolitana, apesar da mesma apresentar e seguir os traços, as características e as nuances de uma metrópole.

Me permito agora descrever os números e dados quantitativos que compõem o mapeamento coordenado por mim e realizado em seis escolas destas três cidades da Região das Hortênsias. Quatrocentos e trinta e um alunos (431), do Colégio Expressão (São Francisco de Paula), do Colégio Estadual José de Alencar (São Francisco de Paula), do Colégio Marista Maria Imaculada (Canela), da Escola Estadual de Ensino Médio Danton Correa da Silva (Canela), do Colégio Cenecista Visconde de Mauá (Gramado) e da Escola Estadual de Ensino Médio Boaventura Ramos Pacheco (Gramado) responderam ao questionário. Destes, aproximadamente $52 \%$ eram do gênero feminino e os outros $48 \%$ do masculino, tendo as escolas o maior percentual dos alunos (42\%) matriculados no $2^{\circ}$ ano do Ensino Médio.

Quando questionados sobre suas preferências, entre as opções que foram apresentadas no questionário, a maioria (82\%) optou por "Música", seguida por "Filmes" (72\%), "Festa(s)" (56\%), "Tecnologia" (52\%) e "Compras" (39\%). Tais dados confirmam que os interesses dos jovens da Região das Hortênsias são bastante semelhantes ao da juventude de qualquer outro lugar do Brasil. Ao preencherem as lacunas que estavam em branco, surgiram alguns artefatos ou atividades que merecem destaque como "Games 1 ", "Livros" e "Dança" entre outros. Ao serem solicitados para optarem por um ou mais grupos sociais com os quais se identificam os alunos indicaram os "Baladeiros" 2 " como a principal tribo juvenil, ou a mais numerosa entre eles, com $38 \%$. No entanto, outros grupos também foram assinalados e, apresentam índices bem próximos como os "Estudiosos" (36\%) e os "Esportistas" (34\%). Em rápida análise visual dos questionários percebi, aqui, que os jovens não se identificam sendo apenas 'isto' ou 'aquilo', ou seja, são múltiplos, pois a grande maioria dos participantes optou - nesta questão - por indicar mais de

${ }^{1}$ Jogos digitais/eletrônicos.

${ }^{2}$ Quem frequenta muitas festas, uma espécie de boêmio contemporâneo. um grupo. "Consumistas" (26\%) e "Futebolistas 3 ou Futebolizados" (21\%) também estão entre os grupos mais indicados. O que se confirma, por exemplo, é que muitos são baladeiros e também estudiosos apesar da ambivalência ou antagonismo aparente dos comportamentos, assim como outros tantos podem ser esportistas e não necessariamente futebolistas, ou vice-versa. Condições como consumistas ou o interesse pela tecnologia atravessam culturalmente muitos jovens e, portanto, estas características estão presentes junto aos diversos grupos sociais que se mesclam e criam novas alquimias. Neste mapeamento inicial, o mais importante para dar sequencia à minha tese foi confirmar a hipótese de que há um grupo considerável dos alunos de Ensino Médio que se identificam com o futebol, pois o mesmo foi apontado como o sétimo $\left(7^{\circ}\right)$ item em interesse e o quinto $\left(5^{\circ}\right)$ grupo social. Trata-se de um grupo não hegemônico, mais significativo e que estabelece como outros suas inter-relações com os demais, portanto merecendo análises mais aprofundadas. O próximo passo seria avaliar especificamente esta população que constituiria não só o objeto de pesquisa da tese, mas também me conduziria pelos espaços e campos culturais que frequentam e trafegam, me guiando em um estudo com inspiração etnográfica.

Reavaliei todos os questionários dos alunos que responderam ter interesse em futebol ou que se consideram participantes do grupo dos futebolistas ou futebolizados para obter mais informações e detalhes que pudessem me conduzir nas próximas etapas da pesquisa. Procurei realizar uma leitura e análise, ainda que superficial, dos números e dados quantitativos. Dos quatrocentos e trinta e um (431) entrevistados incialmente, um total de cento e trinta e três (133), ou $31 \%$ do total, se enquadram neste segmento ligado ao futebol. Destes, $71 \%$ são do gênero masculino. Também pude perceber que há escolas onde o número de futebolizados é maior, pois os índices variam de $11 \%$ a $44 \%$. Portanto, aqui já tenho algumas informações importantes: meu universo de pesquisa seria mais com meninos, mas também não poderia excluir as meninas que eventualmente apresentarem características futebolizadas; e evidentemente, haveria espaços (ambientes escolares) em que encontraria mais evidências do que em outros. Além de futebol, os interesses deste grupo giram em torno de Músicas, Filmes, Festas,

\footnotetext{
${ }^{3}$ No idioma espanhol "Fútbolista” significa jogador de futebol.
} 
Tecnologia e Sexo na ordem de preferência. Portanto, podem procurar unir interesses, como por exemplo, no campo da tecnologia optarem por games ou aplicativos que remetem ao futebol. Os futebolizados também se consideram "Esportistas", "Baladeiros", "Estudiosos", "Consumistas" e "Rockeiros". Estas informações são apenas itens iniciais que não satisfaziam por completo a curiosidade do pesquisador, mas que seriam de grande valia para as entrevistas e aplicação de outras ferramentas metodológicas.

Lembro que este estudo se trata de um "recorte" de um dos espaços e tempos da juventude, ou seja, descrevo e analiso, brevemente, comportamentos de jovens de 14 a 18 anos que frequentam a escola na Região das Hortênsias em um período de aproximadamente três a quatro anos. Percorri um caminho investigativo entre os jovens futebolizados com inspiração etnográfica, sendo um estudo descritivo de uma cultura juvenil, com suas linguagens e hábitos, como também das manifestações materiais de suas atividades. Ao contrário de uma etnografia realizada por antropólogos - que estuda e revela os costumes, as crenças e as tradições de uma sociedade, que são transmitidas de geração em geração e que permitem a continuidade de uma determinada cultura ou de um sistema social - penso que esta pesquisa apenas se inspira neste método, pois os fenômenos pós-modernos não têm a condição e a pretensão de se cristalizarem nas sociedades.

\section{FUTEBOLIZADOS}

A pesquisa e mapeamento anteriores, já apontava para um grupo de pouco mais de $30 \%$ (trinta por cento) dos jovens que estão vinculados ao futebol ou que se consideram futebolizados. Os dados daquele estudo também indicavam que esta cultura juvenil (des)(re)construída pela futebolização era múltipla, ou seja, apresentava também outros interesses. A partir destas informações preliminares ao encontrar os futebolizados na escola - identificando os mesmos pelo que vestiam, conversavam, ou pela simples ação de praticar futebol (ou outra atividade que remetia ao mesmo) no intervalo/recreio das instituições de ensino - resolvi aplicar outro questionário (este com objetivos bem específicos que me ajudariam a entender o processo pós-moderno da Futebolização) com os alunos antes de entrevistá-los. Apresento e comento a seguir os dados desta nova pesquisa ${ }^{4}$ que, apesar de ser quantitativa, revelam comportamentos que merecem análises ampliadas. Saliento que este questionário serviu de "ponto de partida" para iniciar as conversações com os alunos sobre futebol e escola.

A primeira pergunta deste questionário era sobre a forma que os jovens acompanham o futebol. Havia duas alternativas das quais eles deviam optar por uma. A grande maioria, ou seja, quase $90 \%$ dos entrevistados responderam que observam a modalidade através da mídia, portanto, têm pouco contato direto (ou in loco) com a mesma, sendo assim, a realidade que eles vivenciam do futebol é em boa medida moldada pelos veículos midiáticos, que não só espetacularizam como também mercantilizam o esporte, promovendo as celebridades e equipes que mais se enquadram e se adaptam para e na sociedade de consumidores, contribuindo para conquistar mais adeptos de determinadas competições ou agremiações. Quero apontar com isso, que torneios e equipes locais, por movimentarem cifras infinitamente menores que as grandes ligas (principalmente as europeias), recebem menos divulgação e espaço na tevê, rádios, jornais, revistas e também na internet. Pelas respostas iniciais, não é de se surpreender que haja uma preferência por competições e equipes estrangeiras por parte dos jovens nas questões seguintes. Também é interessante, nesta primeira pergunta, o índice de meninos e meninas desta cultura juvenil que frequentam os estádios de futebol. Ainda que os números sejam bastante próximos, observamos que o universo masculino ainda possui maiores oportunidades de acessar e ocupar este espaço social.

A segunda questão é sobre a frequencia que os jovens vão aos estádios para assistir jogos de futebol. Como já era esperado, percebemos que são poucos os que têm ou tiveram acesso a este equipamento. A soma dos dados daqueles que nunca estiveram em um estádio, ou que raramente frequentam as arenas esportivas, chega a $60 \%$ (sessenta por cento) do total. Nos dados gerais os números de jogos que assistem

\footnotetext{
${ }^{4}$ Foram submetidos ao questionário um total de 60 alunos (34 meninos e 26 meninas), na faixa etária dos 15 aos 18 anos de idade, das escolas: Colégio Marista Maria Imaculada (privada), Coopec - Cooperativa de Profissionais em Educação de Canela (privada), Escola Estadual de Ensino Médio Danton Correa da Silva (estadual), Escola Estadual de Educação Básica Neusa Mari Pacheco (Estadual), Escola Estadual de Ensino Médio João Correa (estadual), e Escola Municipal de Ensino Fundamental Santa Terezinha (municipal), todas do município de Canela.
} 
anualmente "ao vivo" também vai reduzindo percentualmente e proporcionalmente no sentido contrário ao número de jogos, ou seja, quantos mais jogos por ano no estádio menor é o indice daqueles jovens que conseguem estar presentes ao espetáculo de entretenimento. Novamente chama atenção a diferença entre meninos e meninas. O percentual do gênero feminino que nunca foi a um estádio de futebol para assistir uma partida é o maior desta questão (42\%), o que reforça que os estádios de futebol são um espaço ainda dominado e marcado pelos homens, mesmo diante da modernização das arenas que promoveu setores mais seguros e atrativos para as mulheres. Outro aspecto que merece atenção nesta questão, é a diferença entre os estudantes do ensino privado em relação ao ensino público. O encarecimento dos ingressos, com a consequente elitização dos consumidores do esporte afasta cada vez mais as camadas populares destes espaços. Apenas 14\% (quatorze por cento) dos alunos de instituições particulares nunca foram assistir jogos de futebol nos estádios, muito provavelmente pela proibição dos pais preocupados com a violência cada vez maior nos grandes centros urbanos; enquanto que $38 \%$ (trinta e oito por cento) dos estudantes de escolas estaduais e municipais nunca tiveram acesso a estes locais, não só pelo cuidado dos responsáveis - também em estado de alerta e proteção contra as ações criminosas -, mas também pelo custo que representa assistir a um jogo de futebol in loco. Tal condição não é para todos, pois este entretenimento pode custar parcela significativa dos rendimentos mensais para muitas famílias. Este aspecto também reflete na maneira como os jovens atribuem significados diferenciados ao futebol. Para uns, apenas uma diversão, para outros, uma oportunidade ímpar de ascender socialmente. Expondo as celebridades do futebol e suas carreiras milionárias diariamente, a mídia, cria expectativas para muitos de se tornarem atletas profissionais e trilharem caminhos semelhantes ou até mais exitosos nas fantasias e desejos desta juventude.

Em média, os jovens assistem cerca de dois jogos de futebol por semana (com base nas respostas anteriores, imagina-se que seja a maioria pela tv). Percebe-se também nesta pergunta que o público masculino acompanha o futebol com maior frequencia e, que uma parcela pequena do segmento feminino pode passar mais dias sem assistir jogos de futebol. Poucas meninas acompanham mais de cinco partidas de futebol por semana. No entanto, quais competições assistem estes jovens é o que chama atenção na questão seguinte, quando poderiam optar por mais respostas do que apenas uma competição e/ou torneio. Vejamos o gráfico 1 que destaca as respostas com maiores percentuais.

Gráfico 1 - Quais campeonatos/torneios você acompanha?

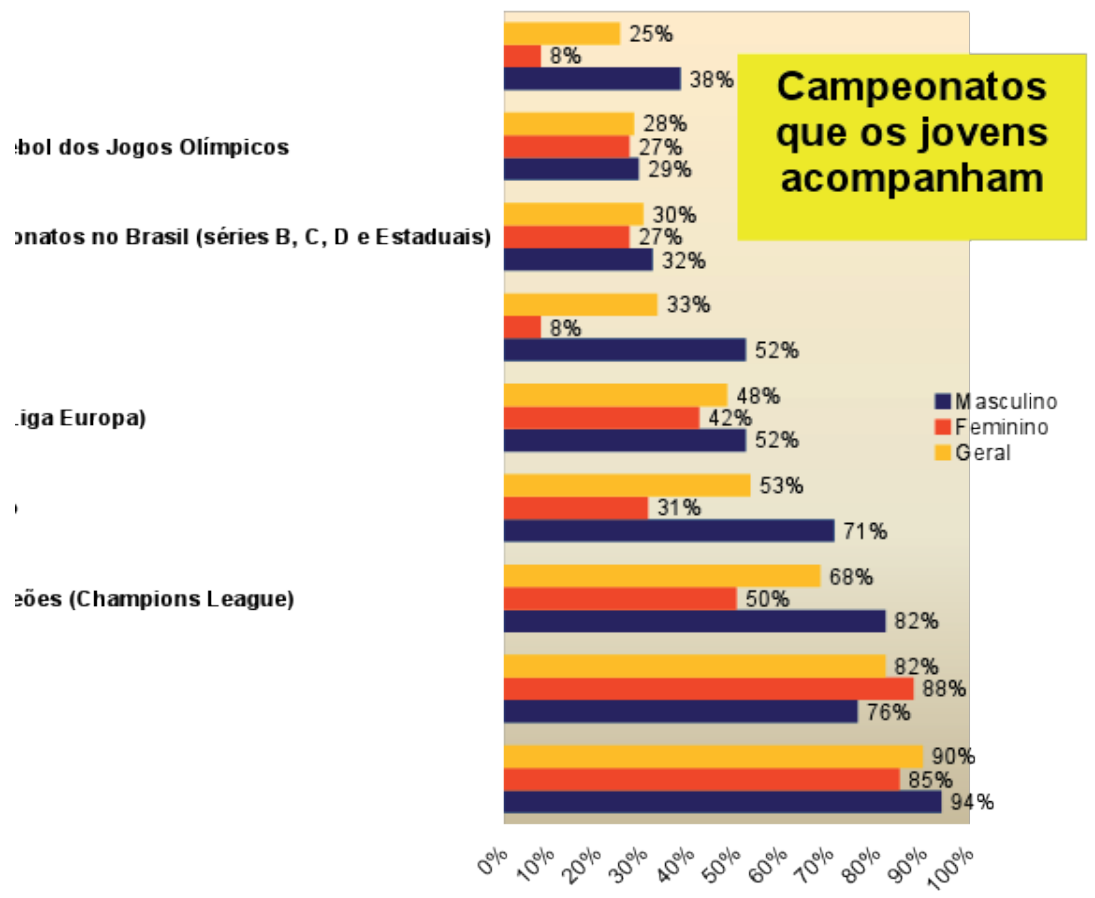

Fonte: Autor 
As principais preferências das respostas na quarta questão deste questionário não chegam a surpreender, pois é natural que o Campeonato Brasileiro seja o mais acompanhado pelos jovens, seguido da Taça Libertadores da América - principal competição continental da América -, pois nos mesmos estão envolvidos os grandes clubes do cenário nacional. $\mathrm{O}$ destaque fica por conta da Champions League, ou Liga dos Campeões, competição que reúne os maiores e mais ricos clubes do futebol mundial (todos com sede na Europa) e, que para as juventudes daqui - com raríssimas exceções - só pode ser acompanhado pela mídia. Inclusive o índice de garotos que prefere a competição do velho continente é maior do que o número daqueles que seguem a Libertadores e, começa a se aproximar do Brasileirão. A Liga Europa - torneio para clubes do segundo escalão europeu - também está entre os cinco campeonatos preferidos pelos jovens futebolizados e, entre as meninas tem maior importância que a Copa do Mundo, uma competição de seleções. O gráfico 1 ainda põe em destaque o Campeonato Espanhol, como a segunda competição nacional preferida, muito provavelmente pela presença de Real Madrid e Barcelona, clubes que obtiveram as maiores conquistas nas duas últimas décadas no futebol mundial e que detém os atletas que protagonizam a escolha do melhor jogador de futebol do mundo nos últimos anos: Cristiano Ronaldo e Messi, respectivamente. Chama atenção ainda que a Eurocopa, para o público masculino, é mais importante que outras competições como a Série B do Campeonato Brasileiro ou o Torneio de Futebol dos Jogos Olímpicos. Também merecem destaque nesta pergunta a Copa América (41\%) e o Campeonato Inglês (32\%) com índices significativos entre os meninos, mas com importância nula para as meninas.

Gráfico 2 - Torce para quantos times?

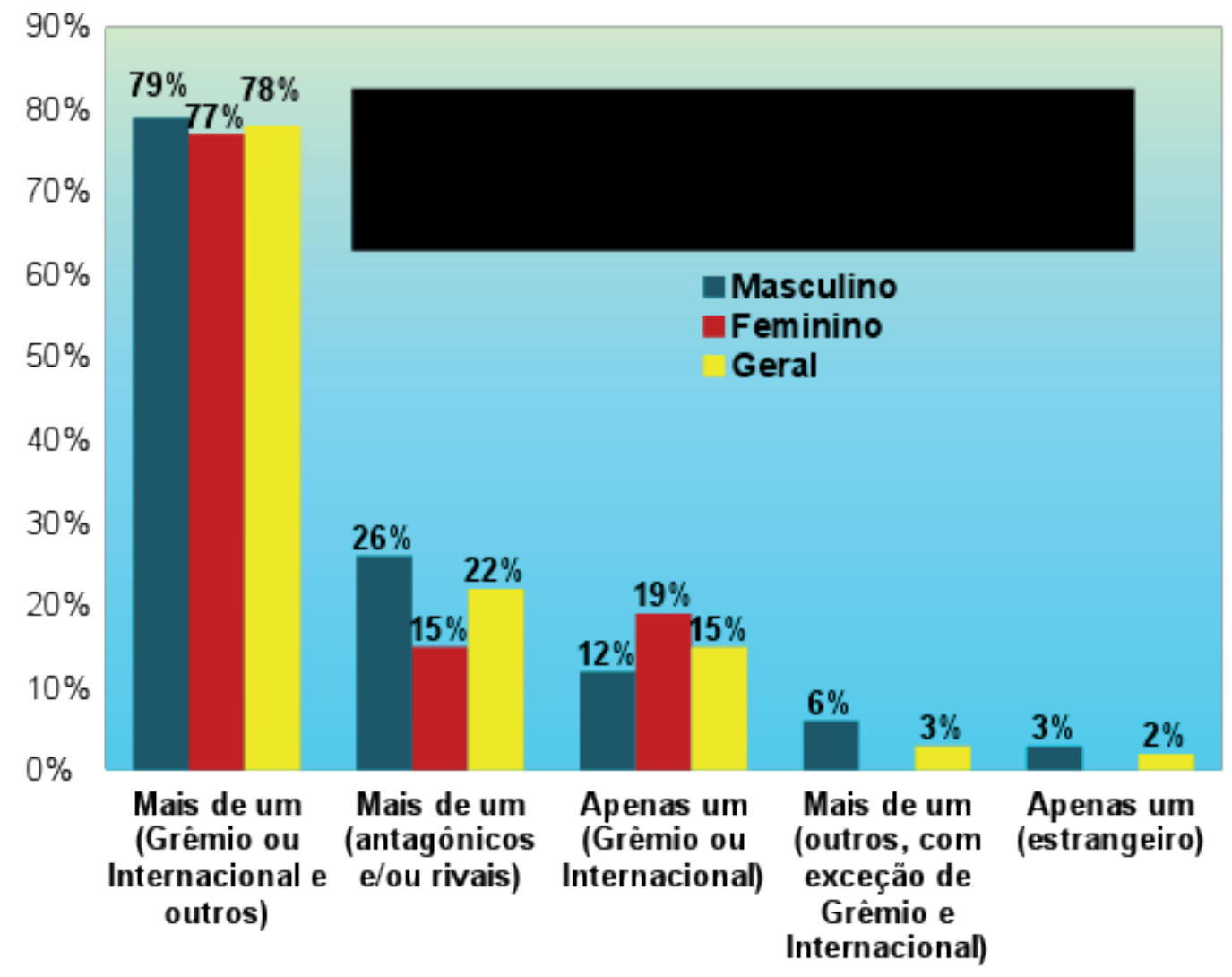

Fonte: Autor

Os dados da quinta pergunta são bastante interessantes. Por estarmos analisando o comportamento de jovens torcedores na região sul do Brasil, e em uma cidade (Canela) próxima ${ }^{5}$ à capital do Rio Grande do Sul (Porto Alegre) é natural que a maioria dos entre-

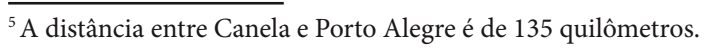


vistados opte por Grêmio ou Internacional como seu clube de futebol preferido. Aqui o que chama atenção são características cada vez mais próximas do torcedor pós-moderno e afastadas da condição moderna. Pelos números, podemos observar que ainda há aqueles com vínculos mais afetivos com um único clube local e, inclusive, esta situação está mais presente no gênero feminino, com quase $20 \%$ (vinte por cento) das entrevistadas sendo torcedoras do Grêmio ou do Inter. O mais significativo é que a absoluta maioria dos jovens contemporâneos torcem para um dos clubes com maior expressão no Estado (pois não podemos identificá-los diretamente como torcedores

Gráfico 3 - Qual(is) destes times você torce?

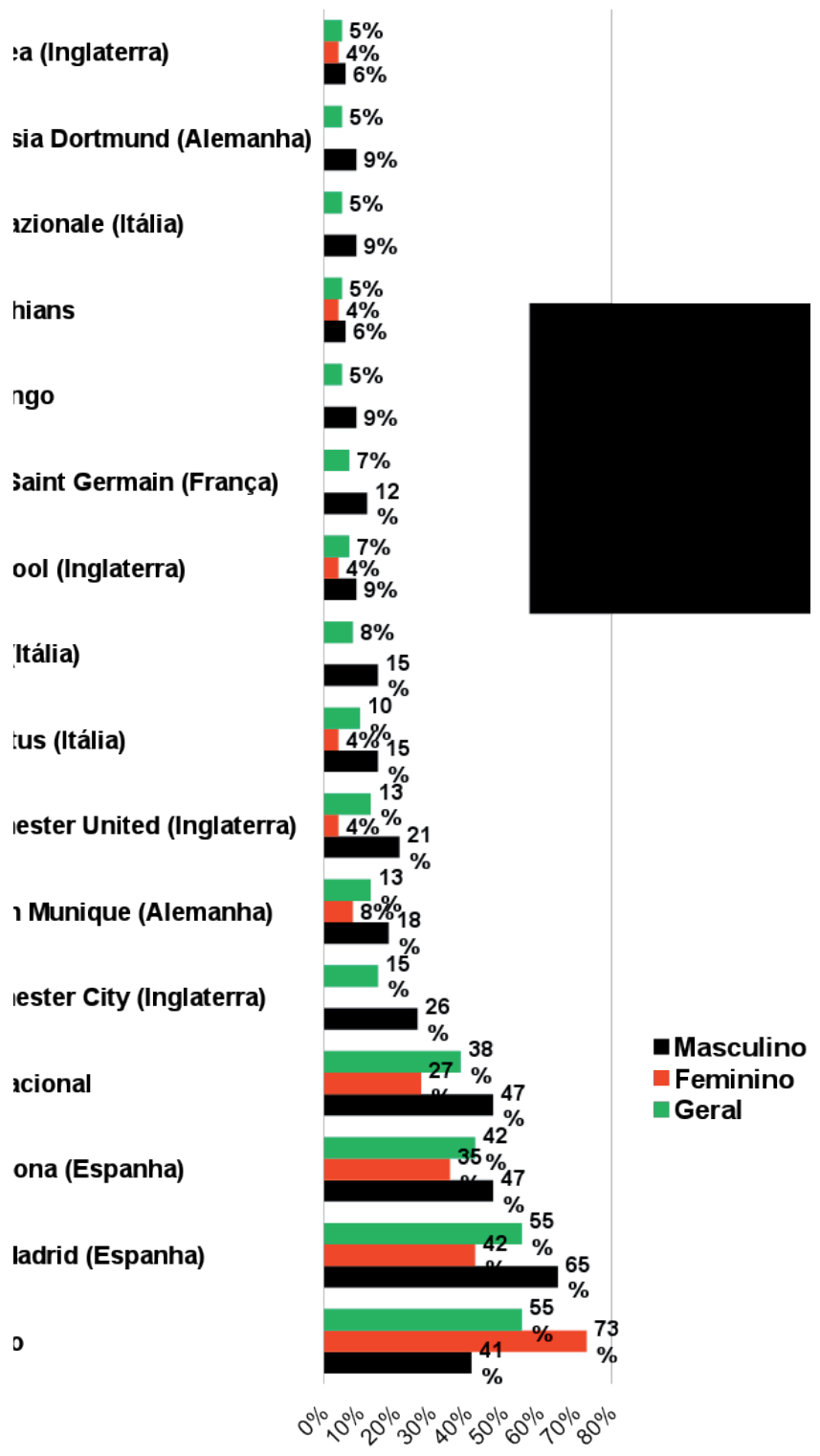

Fonte: Autor de clubes locais e/ou municipais) e também adotam outras agremiações, quase na totalidade estrangeiras como veremos a seguir. Também é curioso o fato de muitos, ao escolherem clubes fora da rivalidade Gre$\mathrm{Nal}$, optarem por seguir equipes que são rivais em território europeu. Nas respostas há uma certa parcela de jovens futebolizados que simpatizam, acompanham e também torcem, ao mesmo tempo, por Real Madrid e Barcelona, Internazionale e Milan, e/ou Manchester United e Manchester City, por exemplo, entre outras rivalidades estrangeiras. Um típico comportamento flâneur, na busca por uma multiplicidade de experiências no futebol, onde as lealdades nacionais podem ser trocadas com base no sucesso competitivo ou na identificação mediada com grandes celebridades. Vejamos quais são (ou eram, pois o comportamento do torcedor pós-moderno é bastante volátil e fugaz) os clubes preferidos dos jovens futebolizados de Canela através das respostas no questionário.

Conforme já havíamos destacado na questão anterior, a cultura juvenil futebolizada se caracteriza por seguir e simpatizar com mais de uma equipe de futebol. Geralmente acompanham um time 'local', por influência familiar e, optam por outra(s) equipes(s), que estão em evidência na mídia pelas suas conquistas recentes ou pelas celebridades da modalidade que possuem em seus plantéis, casos - evidentes na contemporaneidade de Real Madrid e Barcelona, que acabam dividindo a preferência dos jovens com Grêmio e Internacional. Na soma dos números gerais, as equipes espanholas tem mais adeptos que a dupla Gre-Nal; fato que se explica pela seguinte situação: ninguém no Rio Grande do Sul é 'autorizado' a torcer por Grêmio e Internacional simultaneamente, enquanto que o mesmo pode até ser considerado 'normal' para as equipes estrangeiras. Portanto, muitos jovens optaram por responder, quando questionados sobre seu(s) clube(s) preferido(s), Grêmio ou Internacional, mais Real Madrid, Barcelona e outras equipes que também aparecem em destaque nas preferências.

Os campeonatos Inglês, Italiano e Alemão não estão entre os mais assistidos por esta juventude, mas os times deste países recebem importância e atenção dos jovens, muito provavelmente pela presença de atletas ou técnicos celebridades, ou ainda, pelo desempenho dos mesmos nas competições europeias, como a Champions League e a Europa League. Outros clubes, com recentes passagens e destaque na mídia 
- como Palmeiras, Atlético de Madrid, Chapecoense, Monaco e Novo Hamburgo -, também foram citados, mais com indices bem menores e, talvez, com o rápido desaparecimento para a juventude futebolizada. As condições encontradas nestas duas últimas questões se encaixam no debate que Hall (2006) propõe no livro A identidade cultural na pós-modernidade. $\mathrm{O}$ autor afirma que: "[...] as velhas identidades, que por tanto tempo estabilizaram o mundo social, estão em declínio, fazendo surgir novas identidades e fragmentando o indivíduo moderno" (HALL 2006, p.7). Portanto, seguir muitos clubes de futebol - como é o caso dos jovens estudados - nos remete a uma fragmentação das identidades. Podem ser comparadas também, em certa medida, à identidades culturais, que surgem do 'pertencimento'.

O sujeito, previamente vivido como tendo uma identidade unificada e estável, está se tornando fragmentado; composto não de uma única, mas de várias identidades, algumas vezes contraditórias ou não-resolvidas. [...] Esse processo produz o sujeito pós-moderno, conceptualizado como não tendo uma identidade fixa, essencial ou permanente. A identidade torna-se uma "celebração móvel": formada e transformada continuamente em relação às formas pelas quais somos representados ou interpelados nos sistemas culturais que nos rodeiam. [...] O sujeito assume identidades diferentes em diferentes momentos, identidades que não são unificadas ao redor do "eu" coerente. (HALL 2006, pp.12-13)

Interessa ainda saber como se dá o comportamento consumidor destes jovens vinculados ao futebol. Muitos dos acessórios e artefatos futebolizados (camisetas, calções, chuteiras, tênis, meiões, agasalhos e moletons) citados na pesquisa já eram esperados, pois juntamente com o principal objeto da modalidade - a bola - constituem o universo deste esporte. Nesta questão me detenho em analisar brevemente (pois fica aqui um espaço aberto para outra investigação futura) outro artefato deste cenário: os jogos eletrônicos, quarto item na preferência geral $(52 \%)$ e segundo entre os meninos $(73 \%)$. Estes games, permitem aos aficionados tornarem-se imediatamente parte das equipes que escolhem (como manager do 'clube imaginado') para os confrontos virtuais, abrindo ferramentas para que os jovens 'contratem' os melhores atletas e executem esquemas táticos, talvez, nunca imaginados pelos treinadores profissionais, com a vantagem de que se algo der errado, basta reiniciar o jogo, escolher uma nova equipe, contratar atletas, optar por uma formação, e literalmente como os próprios dizem: "Ver no que vai dar ....". A maior entidade do futebol mundial, a FIFA, alimenta esta condição, pois anualmente premia o melhor jogador do game que leva seu próprio nome e, com o qual também fatura milhões em dinheiro (além de novos aficionados). Mais uma vez, é uma característica e comportamento do torcedor flâneur que se torna evidente nas observações que realizei. A interação com o futebol ocorre midiaticamente e eletronicamente. O habitat natural é a "arena virtual", buscando sensações do futebol representadas pelos games, com a identidade baseada no movimento constante, cada vez mais em termos virtuais, mudando de clube como se muda de canal de televisão, buscando sensações, excitação, e simpatizando com diversas agremiações esportivas, jogadores e nações.

\section{CONSIDERAÇÕES}

Há muitas análises em torno desta condição juvenil que ainda merecem e requerem maior aprofundamento através de entrevistas com os sujeitos de forma individual ou em grupo. No entanto, há afirmações e conclusões que podem ser apontadas a partir dos dados que já foram tabulados e apresentados. Descrevo, aqui, a cultura juvenil futebolizada da Região das Hortênsias, especialmente, do município de Canela (Rio Grande do Sul), que apresenta traços muito próximos do que Giulianotti (2012) caracteriza como o torcedor pós-moderno ou flâneur. Em resumo, a futebolização dos jovens produz um sujeito com poucos vínculos com os clubes locais e, muito mais interessado no sucesso - ainda que muitas vezes passageiro - de agremiações e celebridades estrangeiras, ou então, com os caminhos - talvez desconexos - que jovens estrelas do futebol brasileiro trilham em território europeu na busca pela redenção profissional na modalidade e, porque não, também na vida.

\section{REFERÊNCIAS}

ALABARCES, Pablo. Cidadania e narrativas nacionais do futebol argentino contemporâneo. Eco-Pós. Brasil, v.5, $\mathrm{n}^{\mathrm{o}} 1$, p.27-36, 2002. 
ANDRADE, Paula Deporte de. Pedagogias Culturais: as condições teóricas que possibilitaram a emergência do conceito. Anais do $6^{\circ}$ Seminário Brasileiro de Estudos Culturais e Educação (SBECE) e $3^{\circ}$ Seminário Internacional de Estudos Culturais e Educação (SIECE). Canoas (RS), $1^{\circ}$ a 03 de junho de 2015.

ANDRADE, Paula Deporte de; COSTA, Marisa Vorraber. Usos e possibilidades do conceito de pedagogias culturais nas pesquisas em estudos culturais em educação. Textura, Canoas, v.17, n.34, pp.48-63, mai./ago. 2015.

ARAÚJO, Allyson Carvalho de. O esporte como a mais bela marginalidade da vida: articulando estética, comunicação e cultura. In: HELAL, Ronaldo; AMARO, Fausto (orgs.). Esporte e mídia: novas perspectivas: a influência da obra de Hans Ulrich Gumbrecht. Rio de Janeiro: EdUERJ, 2015.

BAUMAN, Zygmunt. Modernidade Líquida. Tradução Plínio Dentzien. Rio de Janeiro: Zahar, 2001.

BERTÊ, Ana Maria de Aveline; LEMOS, Bruno de Oliveira; TESTA, Grazieli; ZANELLA, Marco Antonio Rey; OLIVEIRA, Suzana Beatriz de. Perfil Socioeconômico COREDE Hortênsias. Boletim Geográfico do Rio Grande do Sul. Porto Alegre, n. 26, pp.336-371, fev. 2016.

CANCLINI, Nestor Garcia. Introdução à edição de 2001 - Culturas híbridas em tempos de globalização. In: CANCLINI, Nestor Garcia. Culturas Híbridas. São Paulo: EDUSP, 2003.

DAMO, Arlei Sander. Futebol, engajamento e emoção. In: HELAL, Ronaldo; AMARO, Fausto (orgs.). Esporte e mídia: novas perspectivas: a influência da obra de Hans Ulrich Gumbrecht. Rio de Janeiro: EdUERJ, 2015.

DEBORD, Guy. A Sociedade do Espetáculo. Lisboa: Edições Antipáticas, 2005.

GIULIANOTTI, Richard. Sociologia do futebol: dimensões históricas e socioculturais do esporte das multidões. Tradução Wanda Nogueira Caldeira Brandt e Marcelo de Oliveira Nunes. São Paulo: Nova Alexandria, 2010.

Fanáticos, seguidores, fãs e flâneurs: uma taxonomia de identidades do torcedor no futebol. Recorde: Revista de História do Esporte. Volume 5, Número 1, p.135, junho de 2012.

HALL, Stuart. A centralidade da cultura: notas sobre as revoluções culturais do nosso tempo. Educação \& Realidade, Porto Alegre, v.22, nº 2, p.15-46, jul/dez 1997.

A identidade cultural na pós-modernidade. Tradução Tomaz Tadeu da Silva e Guacira Lopes Louro. 11 ed. Rio de Janeiro: DP\&A, 2006.

$\mathrm{KOCH}$, Rodrigo. Marcas da futebolização na cultura e na educação brasileira. Dissertação (Mestrado em Educação).
ULBRA, Programa de Pós-Graduação em Educação, Canoas, 2012.

KOFF, Fábio André. Dando tratos à bola. In: CLUBE DOS 13. The Best Football in the World. Material de divulgação da entidade, Porto Alegre/São Paulo, 2009.

LIPOVETSKY, Gilles. Da leveza: rumo a uma civilização sem peso. Tradução Idalina Lopes. Barueri, SP: Manole, 2016.

SILVA, Juremir Machado da. A sociedade midíocre. Passagem ao hiperespetacular: o fim do direito autoral, do livro e da escrita. Porto Alegre; Sulina, 2012.

STEINBERG, Shirley R. Kindercultura: a construção da infância pelas grandes corporações. In: SILVA, Luiz Heron da; AZEVEDO, José Clóvis de; SANTOS, Edmilson Santos dos (Orgs.). Identidade Social e a Construção do Conhecimento. Porto Alegre: SMED, 1997.

Recebido em: 13.06.2017

Aceito em: 24.08.2017 